\title{
Research on Heat Source Model and Weld Profile for Fiber Laser Welding of A304 Stainless Steel Thin Sheet
}

\author{
Peizhi Li, ${ }^{1}$ Yu Fan $\mathbb{D D}^{1}{ }^{1}$ Chonghao Zhang, ${ }^{2}$ Zhiyuan Zhu, ${ }^{3}$ Wenteng Tian, ${ }^{1}$ and Anmin Liu ${ }^{4}$ \\ ${ }^{1}$ School of Materials Science and Engineering, China University of Mining and Technology, Xuzhou, Jiangsu 221116, China \\ ${ }^{2}$ Changzhou CAM. TG. Laser Equipment Co., Ltd., Changzhou, Jiangsu 213000, China \\ ${ }^{3}$ School of Materials Science and Engineering, Jiangsu University of Science and Technology, Zhenjiang, Jiangsu 212003, China \\ ${ }^{4}$ Changzhou College of Information Technology, Changzhou, Jiangsu 213164, China \\ Correspondence should be addressed to Yu Fan; fanyu@cumt.edu.cn
}

Received 19 November 2017; Accepted 4 March 2018; Published 22 April 2018

Academic Editor: Paolo Ferro

Copyright (c) 2018 Peizhi Li et al. This is an open access article distributed under the Creative Commons Attribution License, which permits unrestricted use, distribution, and reproduction in any medium, provided the original work is properly cited.

\begin{abstract}
A heat source model is the key issue for laser welding simulation. The Gaussian heat source model is not suitable to match the actual laser weld profile accurately. Furthermore, fiber lasers are widely recognized to result in good-quality laser beam output, a narrower weld zone, less distortion, and high process efficiency, compared with other types of lasers (such as $\mathrm{CO}_{2}, \mathrm{Nd}: \mathrm{YAG}$, and diode lasers). At present, there are few heat source models for fiber laser welding. Most of researchers evaluate the weld profile only by the bead width and depth of penetration, which is not suitable for the laser keyhole welding nail-like profile. This paper reports an experimental study and FEA simulation of fiber laser butt welding on $1 \mathrm{~mm}$ thick A304 stainless steel. A new heat source model (cylindrical and cylindrical) is established to match the actual weld profile using Marc and Fortran software. Four bead geometry parameters (penetration depth, bead width, waist width, and depth of the waist) are used to compare between the experimental and simulation results. The results show that the heat source model of cylindrical and cylindrical can match the actual shape of the fiber laser welding feasibly. The error range of the penetration depth, bead width, waist width, and depth of the waist between experimental and simulation results is about $4.1 \pm 1.6 \%, 2.9 \pm 2.0 \%, 13.6 \pm 7.4 / \%$, and $18.3 \pm 8.0 \%$, respectively. In addition, it is found that the depth of penetration is more sensitive to laser power rather than bead width, waist width, and depth of the waist. Welding speed has a similar influence on the depth of penetration, weld width, waist width, and depth of the waist.
\end{abstract}

\section{Introduction}

Stainless steel sheet is widely used in the welded structure of biopharmaceutical, medical device, aerospace, and precision instrument manufacturing industry because of its characteristic of smooth surface, nonmagnetic performance, and corrosion resistance [1]. Currently, the common welding methods are MIG-MAG, TIG, and laser welding [2-4]. Compared to the methods of MIG-MAG and TIG, laser welding offers a number of attractive features such as high power density, high speed, narrow weld, and small deformation.

Since the weld profile (depth of penetration, weld width, etc.) is an important criterion to evaluate the quality of laser welding and the results of numerical simulation, the weld profile of laser welding is studied by many scholars [5-8]. Tadamalle et al. [9] investigate the influence of pulsed $\mathrm{Nd}$ :YAG laser welding process parameters on weld pool geometry. The results show that the bead width and depth of penetration decrease as the welding speed increases. Liao and $\mathrm{Yu}[10]$ investigate that effect of the pulsed Nd:YAG laser welding incident angle on the depth of penetration, bead width, and bead length, and the results show that the bead width and depth of penetration decrease with the increase in incident angle. Balasubramanian et al. [11] conduct experiments using a three-dimensional conical Gaussian heat source and the temperature-dependent thermophysical properties of the A304 stainless steel sheet to be employed 
for performing a nonlinear transient thermal analysis. The results of numerical simulation match the actual shape of the weld well, and the depth of penetration and bead width increase as the welding power increases, while the depth of penetration and bead width decrease as the welding speed increases. Shanmugam et al. [12] used a three-dimensional conical Gaussian heat source as a heat source model for studying temperature profiles in the A304 stainless steel sheet. The results of numerical simulation match the actual shape of the weld well, and the calculated weld pool shapes resemble the experimentally measured weld pool shapes. The error percentage of the bead width and depth of penetration is about $7-8 \%$.

Laser welding is a complex physical and chemical process, and many researchers have done a lot of research on this process [9-13]. However, the study of the welding temperature field is a prerequisite for the analysis of welding stress and deformation [1]. It is very important to measure accurately the welding temperature field. Fortunately, with the computer simulation technique used in welding disciplines, the computer simulation technique provides a fast and effective method for measurement of the temperature field. At present, many researchers sum up many combination heat source models for numerical simulation of the temperature field of laser welding of stainless steel. Kim et al. [14] design the combination heat source model of conical and inverted conical to simulate the temperature field of pulsed Nd:YAG laser welding of A304 stainless steel in different conditions. The maximum error of the bead width and depth of penetration is about $0.132 \mathrm{~mm}$ (13\%). Chukkan et al. [15] simulate the pulsed Nd:YAG laser beam welding profile, temperature field, and welding stress using three combination heat source models (conical, double ellipsoid, and conical, conical, and cylindrical). The calculated weld pool shapes of three combination heat source models resemble the experimentally measured weld pool shapes with a maximum error about $0.082 \mathrm{~mm}(5.5 \%), 0.13 \mathrm{~mm}(8.7 \%)$, and $0.02 \mathrm{~mm}(1.3 \%)$, respectively. The results of numerical simulation using conical and cylinder are more accurate than others. Shi et al. [16] establish the combination heat source model of conical, inverted conical, and ellipsoid to simulate the heat source of laser lap welding of stainless steel car body. The error of the bead width and depth of penetration is less than $0.092 \mathrm{~mm}(8.0 \%)$.

Many researchers sum up some combination heat source models for pulsed Nd:YAG laser welding or $\mathrm{CO}_{2}$ laser welding. However, there are no well heat source models for fiber laser welding of the A304 stainless steel sheet. There are a wide variety of laser types available for welding, each of which has its own specific characteristics [17]. Unlike most other types of lasers, the wavelength of the fiber laser is about $1.06 \mu \mathrm{m}$ and the attenuation of the fiber laser is about $10 \mathrm{~dB} / \mathrm{km}$. Fiber lasers offer a compact, electrically efficient alternative to Nd:YAG technology. Furthermore, other researchers evaluated the weld profile only by the bead width and depth of penetration. So, in this paper, fiber laser butt welding of A304 stainless steel of thickness $1 \mathrm{~mm}$ is carried out to study the change of weld profile in different conditions, and a new heat source model is established to match
TABLe 1: Chemical compositions (wt.\%) of A304 stainless steel.

\begin{tabular}{lccccccc}
\hline $\mathrm{C}$ & $\mathrm{Si}$ & $\mathrm{Mn}$ & $\mathrm{P}$ & $\mathrm{S}$ & $\mathrm{Ni}$ & $\mathrm{Cr}$ & $\mathrm{Fe}$ \\
\hline 0.0630 & 0.6880 & 1.1450 & 0.0275 & 0.0001 & 8.8250 & 18.2675 & Bal. \\
\hline
\end{tabular}

the actual weld profile using Marc and Fortran software. The combination heat source mode of cylindrical and cylindrical is employed for performing a nonlinear transient thermal analysis. The weld pool shapes are evaluated by the weld width, depth of penetration, waist width, and depth of the waist. The correct heat source model is a solid foundation to analyze temperature field, welding stress, and deformation.

\section{Experimental Materials and Procedure}

In this experimental work, an A304 stainless steel workpiece of $100 \times 100 \times 1 \mathrm{~mm}$ thick sheet is chosen. The chemical compositions of the materials are shown in Table 1.

A MFSC-500W fiber laser welding machine (Maxphotonics, Shenzhen, China) is used for all experiments. The materials are completely cleaned prior to welding. The laser wavelength is $1.06 \mu \mathrm{m}$, and the maximum output power is $500 \mathrm{~W}$. During the welding process, the plates are fixed by a fixture to prevent deformation. An argon volume fraction of $99.999 \%$ is used as shielding gas to avoid atmospheric contamination. In the same conditions, the first set of the experiment is conducted by varying the laser power from $200 \mathrm{~W}$ to $400 \mathrm{~W}$ and the second set of the experiment is conducted by varying the welding speed from $0.4 \mathrm{~m} / \mathrm{min}$ to $2 \mathrm{~m} / \mathrm{min}$. The process parameters in different conditions are given in Table 2. The way of fixing the plates is shown in Figure 1.

A304 stainless steel plates are butt welded according to the welding parameters in Table 2, and the size of samples which are cut in the welded joints is $10 \times 10 \times 1 \mathrm{~mm}$. The samples are grounded with 240-, 400-, 800-, and 1200-mesh silicon carbide papers and polished to a mirror finish. Then, the weld profile in different welding parameters is observed using a metalloscope in 100x. Before the simulation, a $2 \mathrm{~mm}$ thick A304 stainless steel thin sheet was used for trial welding. The actual welding situation is simulated using Marc and Fortran software by mesh generation, with material properties, boundary conditions, heat source model, and so on. The results of simulation are compared with the actual result to verify the correctness of the model.

\section{Finite Element Analysis}

3.1. Model and Mesh Generation. Figure 2(a) shows the analysis model. Due to the structural characteristics of A304 stainless steel sheet butt welding and geometric symmetry, only one plate is used to reduce the simulation computation time. A fine mesh is used for areas in contact with the laser beam since they experienced a complicated thermal sequence of momentary heating and cooling. The size of elements becomes larger from the center of the weld to reduce the calculating time. The size of elements is $0.2 \times 0.2 \times 0.25 \mathrm{~mm}$ in the weld; while far away from the weld, the size of elements is $0.2 \times 0.2 \times 0.25 \mathrm{~mm}$; after the 
TABLE 2: Process parameters of laser welding in different conditions.

\begin{tabular}{lcccc}
\hline Number & Power $(\mathrm{W})$ & Welding speed $(\mathrm{m} / \mathrm{min})$ & Focus position $(\mathrm{mm})$ & Gas pressure $(\mathrm{MPa})$ \\
\hline 1 & 200 & 2 & 0 & 0.15 \\
2 & 250 & 2 & 0 & 0.15 \\
3 & 300 & 2 & 0 & 0.15 \\
4 & 350 & 2 & 0 & 0.15 \\
5 & 400 & 2 & 0 & 0.15 \\
6 & 250 & 2 & 0 & 0.15 \\
7 & 250 & 1.6 & 0 & 0.15 \\
8 & 250 & 1.2 & 0 & 0.15 \\
9 & 250 & 0.8 & 0 & 0.15 \\
10 & 250 & 0.4 & 0.15 \\
\hline
\end{tabular}

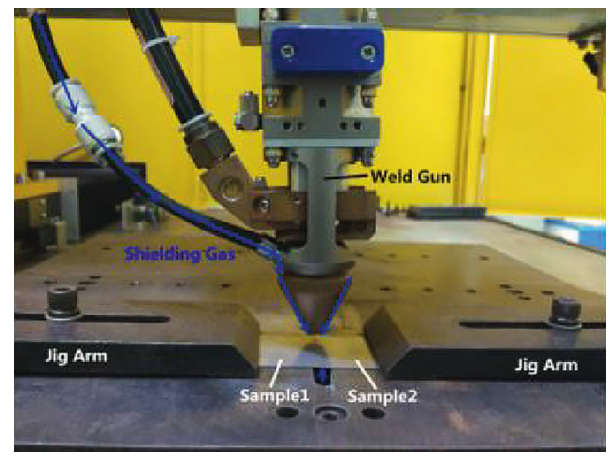

(a)

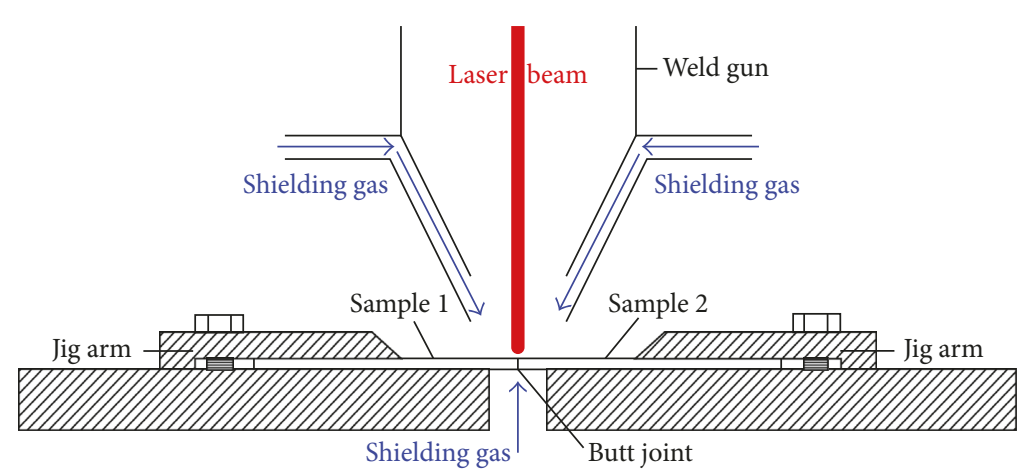

(b)

Figure 1: (a) The way of fixing the plates; (b) schematic diagram.

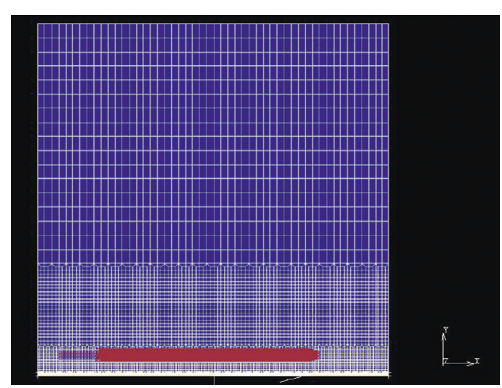

(a)

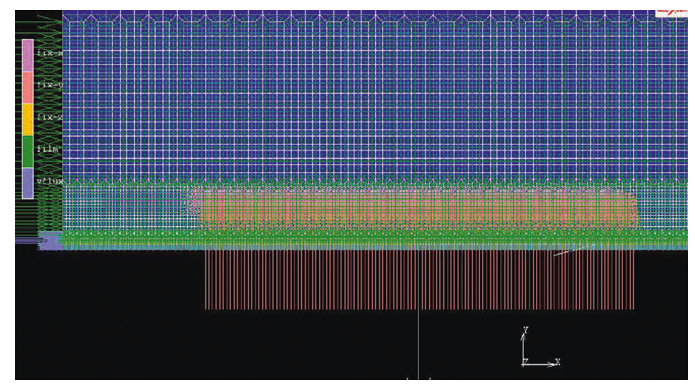

(b)

Figure 2: (a) Model and mesh generation; (b) boundary conditions.

second and the third transitions, the size of elements is $0.4 \times 0.4 \times 0.25 \mathrm{~mm}$ and $1.6 \times 1.6 \times 0.25 \mathrm{~mm}$, respectively. The number of elements and nodes is 34400 and 44425 , respectively. The type of the element is HEX8.

3.2. Material Properties and Boundary Conditions. The physical properties of A304 stainless steel are quoted directly from Marc. Thermal-physical properties of A304 stainless steel are shown in Table 3. The initial temperature of the environment is $20^{\circ} \mathrm{C}$. When defining boundary conditions, three directions $(X, Y, Z)$ of the specimen are designed according to the actual situation to ensure zero displacement. The heat exchange between the base metal and the
TABLE 3: Thermal-physical properties of A304 stainless steel.

\begin{tabular}{lccc}
\hline $\begin{array}{l}\text { Temperature } \\
\left({ }^{\circ} \mathrm{C}\right)\end{array}$ & $\begin{array}{c}\text { Thermal } \\
\text { conductivity } \\
\left(10^{2} \mathrm{~W} /\left(\mathrm{m} \cdot{ }^{\circ} \mathrm{C}\right)\right)\end{array}$ & $\begin{array}{c}\text { Specific heat } \\
\text { capacity } \\
\left(10^{3} \mathrm{~J} /\left(\mathrm{kg} \cdot{ }^{\circ} \mathrm{C}\right)\right)\end{array}$ & $\begin{array}{r}\text { Density } \\
\left(10^{4} \mathrm{~kg} / \mathrm{m}^{3}\right)\end{array}$ \\
\hline 0 & 0.15 & 0.46 & 0.79 \\
245 & 0.17 & 0.51 & 0.78 \\
500 & 0.20 & 0.50 & 0.77 \\
800 & 0.22 & 0.61 & 0.75 \\
1000 & 0.24 & 0.66 & 0.74 \\
1200 & 0.26 & 0.74 & 0.73 \\
1400 & 0.28 & 1.59 & 0.72 \\
1500 & 0.40 & 1.59 & 0.71 \\
2000 & 0.68 & 0.76 & 0.67 \\
2800 & 0.80 & 0.65 & 0.59 \\
\hline
\end{tabular}




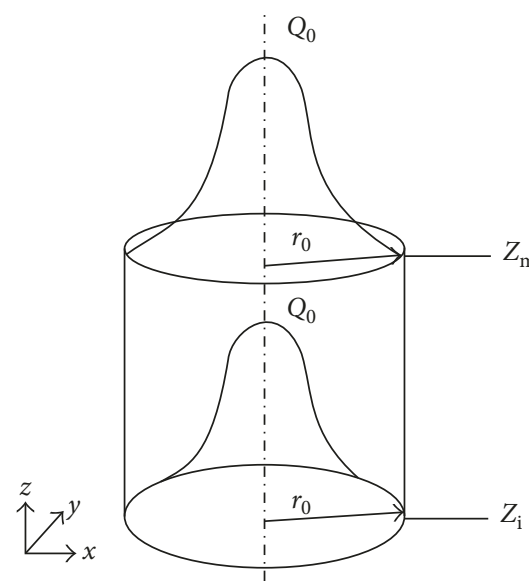

(a)

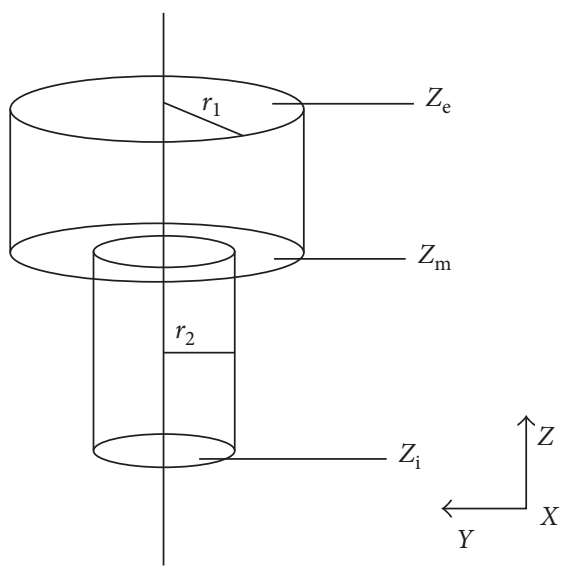

(b)

Figure 3: (a) Gaussian cylindrical heat source model [15]; (b) combination heat source mode of cylindrical and cylindrical.

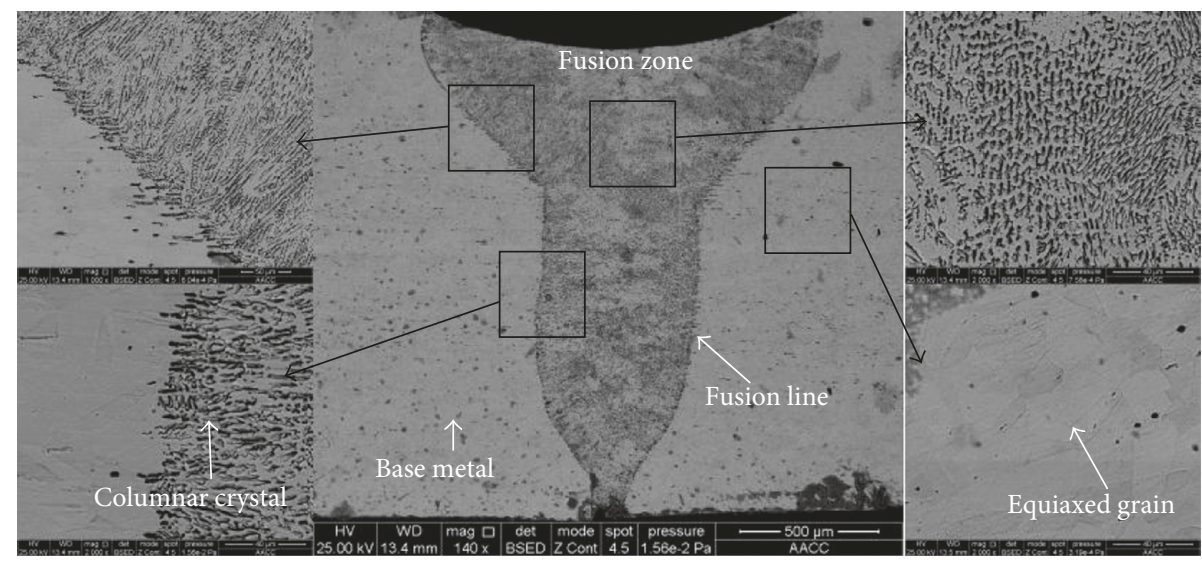

FIGURE 4: SEM micrographs of the trial welding sample.

environment is going in the welding process and is ignored between the base metal and the fixture. The heat exchange is designed as surface heat transfer, the temperature of the environment is $20^{\circ} \mathrm{C}$, and the heat transfer coefficient is 0.04 . Then, the boundary condition of heat input needs to be defined. There is no heat affected zone in the laser welding A304 stainless steel welded joint. A new subroutine is created about the heat source model by Fortran and applied to the weld. Figure 2(b) shows the boundary conditions.

3.3. Heat Source Model. It has a great relationship between the selection of the heat source model and the weld profile [18]. The weld profile is nail shaped, as shown in Figure 6. According to the weld profile, the combination heat source mode of cylindrical and cylindrical is designed for numerical simulation. Figure 3(a) shows the Gaussian cylindrical heat source model. In Figure $4, Q_{0}$ is the maximum intensity, $r_{0}$ is the radius of the cylindrical shell, and $Z_{\mathrm{e}}$ and $Z_{\mathrm{i}}$ are the locations of the upper and lower surface. The heat input of this source can be expressed as follows:

$$
Q_{r}=Q_{0} \exp \left(-\frac{3 r^{2}}{r_{0}^{2}}\right), \quad r^{2}=x^{2}+y^{2},
$$

where $Q_{r}$ is the heat source intensity in $r, Q_{0}$ is the maximum intensity, and $r_{0}$ is the radius of the cylindrical shell.

Figure 3(b) shows the combination heat source mode of cylindrical and cylindrical. In Figure $5, Z_{\mathrm{e}}, Z_{\mathrm{m}}$, and $Z_{\mathrm{i}}$ are the locations of the upper, middle, and lower surface; $r_{1}$ is the radius of the upper cylindrical; and $r_{2}$ is the radius of the lower cylindrical. The essence of the three-dimensional cylindrical heat source is superposition of a series of Gaussian planes along the thickness direction. The power distribution ratio between upper cylindrical and lower cylindrical is $0.54: 0.46$. The parameters of the combination heat source mode of cylindrical and cylindrical are shown in Table 4.

\section{Results and Discussion}

4.1. Experimental Results. The microstructure of the trial welding sample is shown in Figure 4. The weld pool shapes of fiber laser welding A304 stainless steel are like nail which is 

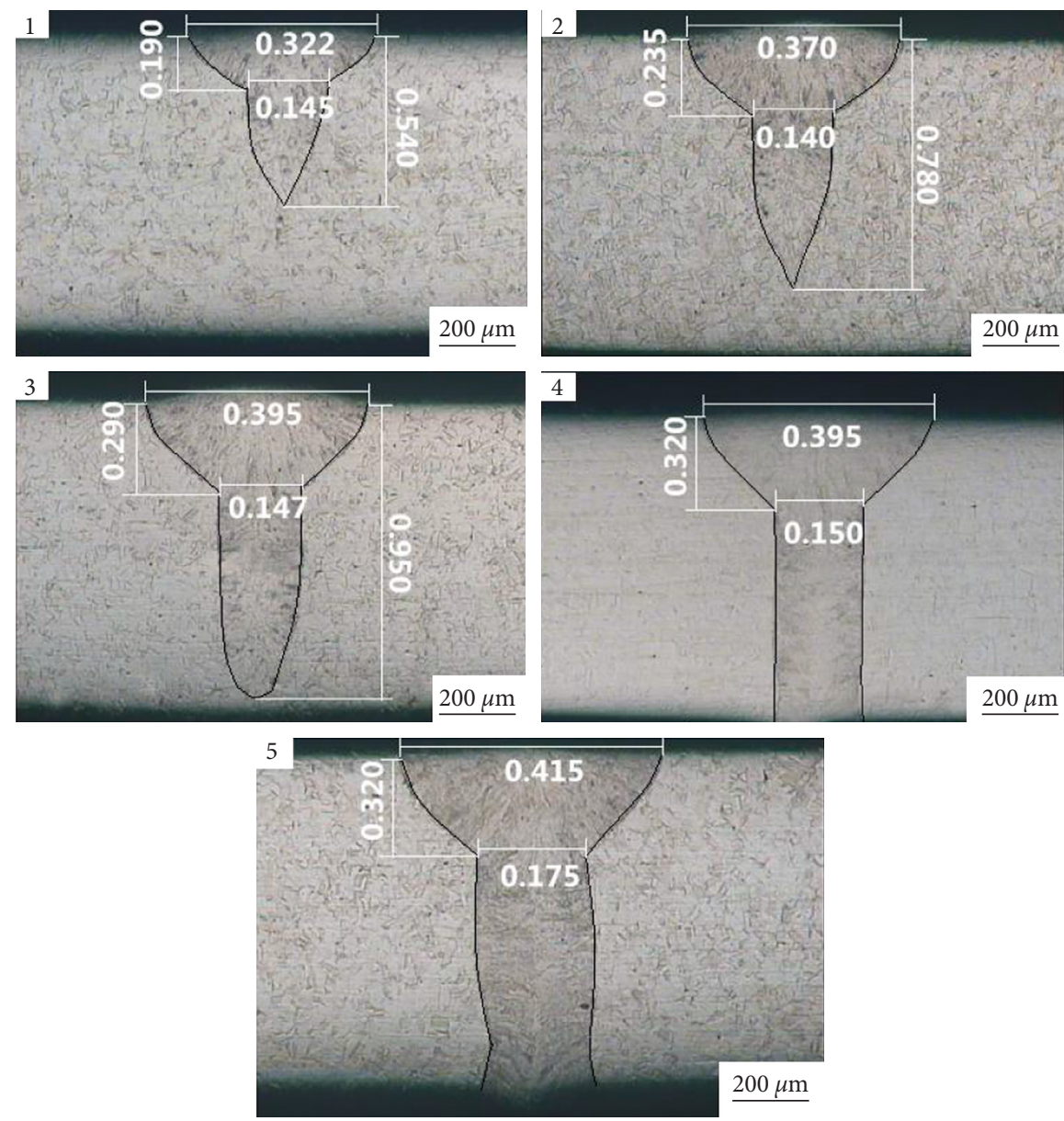

Figure 5: Weld profile for different laser powers. (1) $200 \mathrm{~W}$; (2) $250 \mathrm{~W}$; (3) $300 \mathrm{~W}$; (4) $350 \mathrm{~W}$; (5) $400 \mathrm{~W}$.

typically the shape of laser keyhole welding. Laser power brings A304 stainless steel to vaporization, after few milliseconds of irradiation, and it is termed as keyhole welding. The pressure created by the intense vaporization tends to dig the molten metal zone, which allows the laser beam to penetrate deeper, and it makes the irradiated zone a thin hole, known as keyhole [19]. Laser power makes a waist by thermodynamic cycles, fluid flows, and heat transfer phenomena in the upper part of the fusion zone. The parent material and fusion zone could be discriminated easily. The microstructure of the parent material is composed of coarse equiaxed grains (around $20 \mu \mathrm{m}$ ). The grain near the base parent metal did not grow up obviously, so there are no apparent transition zone and heat affected zone in the welded joint. The columnar dendrite, whose orientation is perpendicular to the fusion line, exists in a welding seam. The dendrite arm spacing of the $\delta$-Fe in the fusion zone is about $3.5 \mu \mathrm{m}$. For the reason of high thermal conductivity, large temperature gradient, and slow crystallization rate, the undercooling zone at the edge of the weld is small, which is beneficial for the formation of columnar crystals [20].

The weld profile is shown in Figures 5 and 6 . The change of depth of penetration, weld width, waist width, and depth of the waist in different conditions is analyzed by Figures 5 and 6 . The effect of laser power on the depth of penetration, bead width, waist width, and depth of the waist for butt joint welds at a constant weld speed of $2 \mathrm{~m} / \mathrm{min}$ and focus position of $0 \mathrm{~mm}$ is shown in Figure 7. With the increase of laser power, the depth of penetration increases, but the increase of weld width, waist width, and depth of the waist is not obvious. The increase of weld width, waist width, and depth of the waist is $0.322-0.415 \mathrm{~mm}, 0.145-0.175 \mathrm{~mm}$, and 0.190 $0.320 \mathrm{~mm}$, respectively. So, the depth of penetration is more sensitive to the welding power than bead width, waist width, and depth of the waist. This is due to the increase of laser energy density with the increase of laser power. The area of keyhole increases and the keyhole deepens into the interior of the sheet, which result in the increase of energy absorption and energy concentration in the lower part of the pool. The laser power covers a wide area on the top surface of the sheet. Therefore, there is a slight increase in the bead width of the laser weld [21]. The effect of welding speed on the depth of penetration, bead width, waist width, and depth of the waist for butt joint welds at a constant laser power of $250 \mathrm{~W}$ and focus position of $0 \mathrm{~mm}$ is shown in Figure 8. The depth of penetration, bead width, waist width, and depth of the waist decrease with the increase of welding speed, which is due to the decrease in the amount of heat input and less interaction time period between the laser beam source and the weld material [6]. The decrease range of the depth of penetration, 

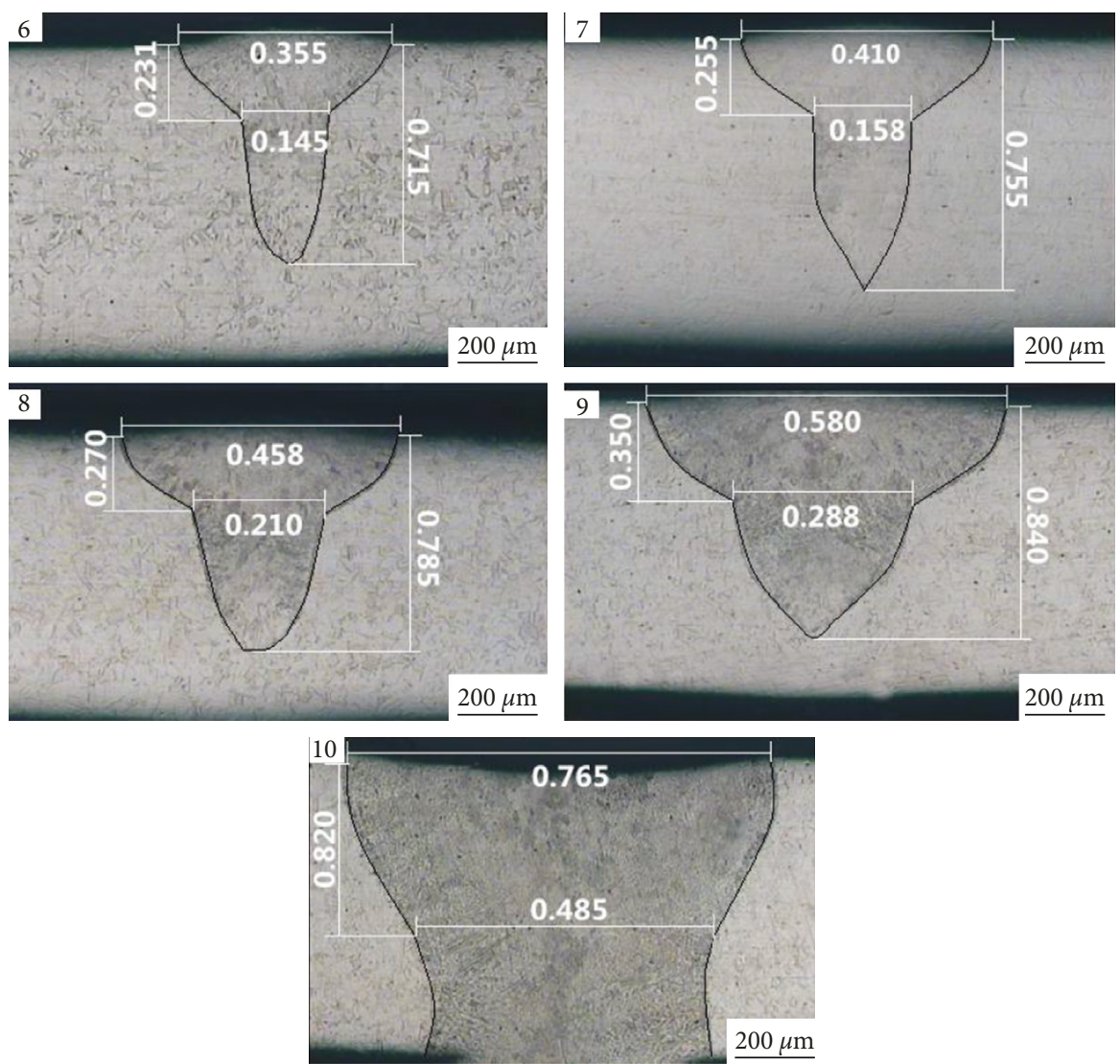

Figure 6: Weld profile for different laser speeds. (6) $2 \mathrm{~m} / \mathrm{min}$; (7) $1.6 \mathrm{~m} / \mathrm{min}$; (8) $1.2 \mathrm{~m} / \mathrm{min}$; (9) $0.8 \mathrm{~m} / \mathrm{min}$; (10) $0.4 \mathrm{~m} / \mathrm{min}$.

TABle 4: Parameters of the combination heat source mode of cylindrical and cylindrical.

\begin{tabular}{lccccc}
\hline $\begin{array}{l}\text { Power distribution } \\
\text { ratio }\end{array}$ & $\begin{array}{c}Z_{\mathrm{e}} \\
(\mathrm{mm})\end{array}$ & $\begin{array}{c}Z_{\mathrm{m}} \\
(\mathrm{mm})\end{array}$ & $\begin{array}{c}Z_{\mathrm{i}} \\
(\mathrm{mm})\end{array}$ & $\begin{array}{c}r_{1} \\
(\mathrm{~mm})\end{array}$ & $\begin{array}{c}r_{2} \\
(\mathrm{~mm})\end{array}$ \\
\hline $0.54: 0.46$ & 1 & 0.9 & 0 & 1 & 0.45 \\
\hline
\end{tabular}

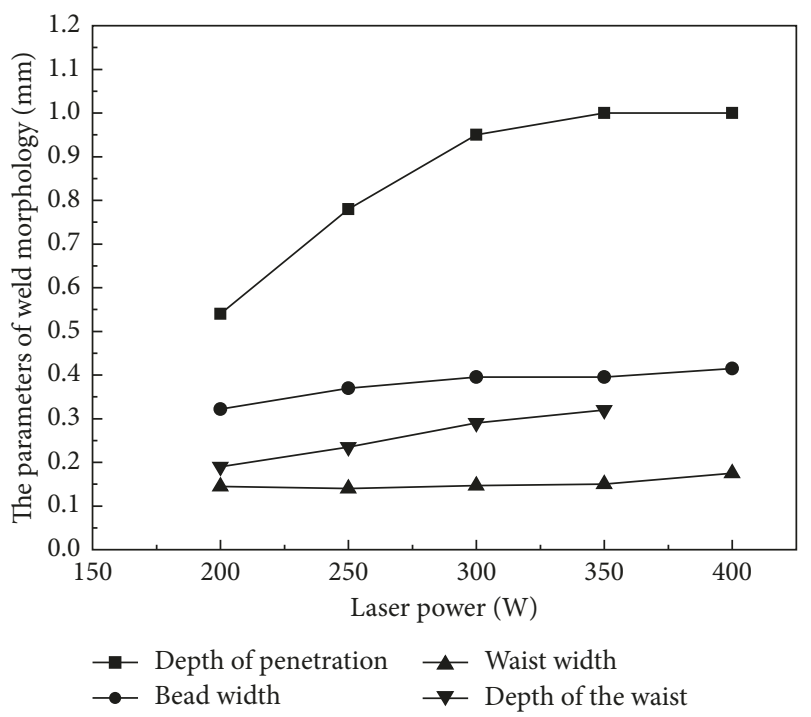

FIGURE 7: Effect of laser power on the depth of penetration, bead width, waist width, and depth of the waist for the butt joint.

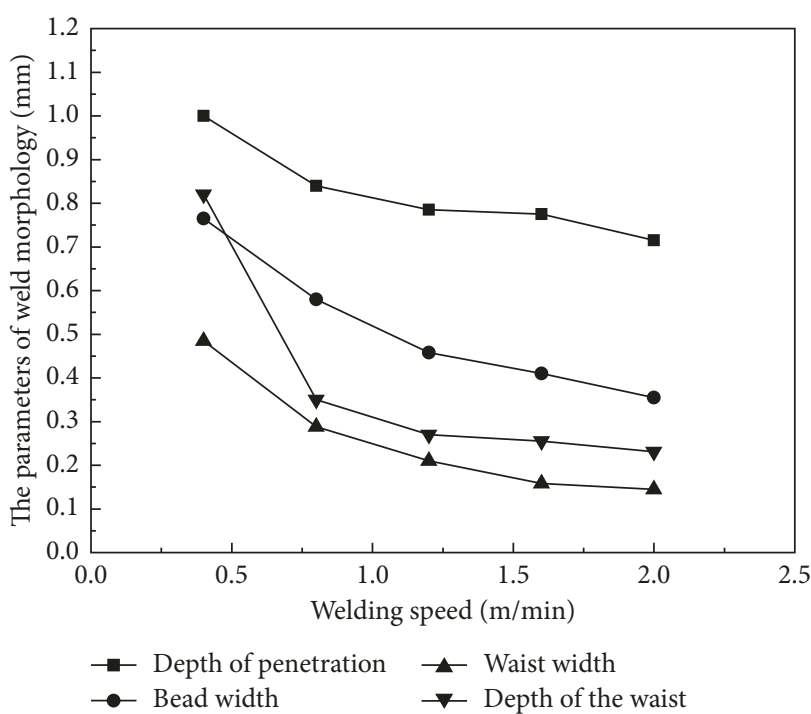

FIGURE 8: Effect of welding speed on the depth of penetration, bead width, waist width, and depth of the waist for the butt joint.

weld width, waist width, and depth of the waist is $1.00-$ $0.715 \mathrm{~mm}, 0.765-0.355 \mathrm{~mm}, 0.485-0.145 \mathrm{~mm}$, and $0.820-$ $0.231 \mathrm{~mm}$, respectively.

Comparing Figure 7 with Figure 8, the change of bead width, waist width, and depth of the waist is more sensitive for welding speed than for laser power. Welding speed has 


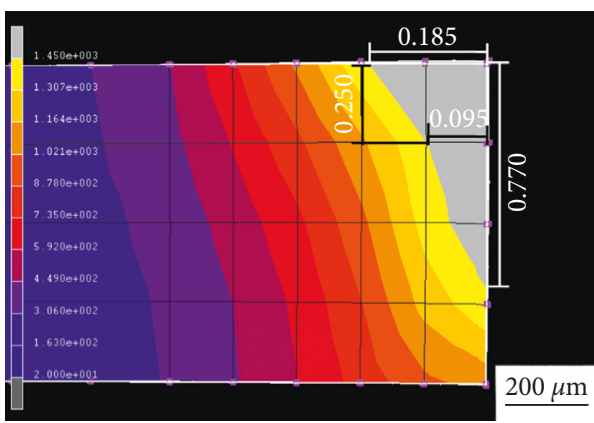

(a)

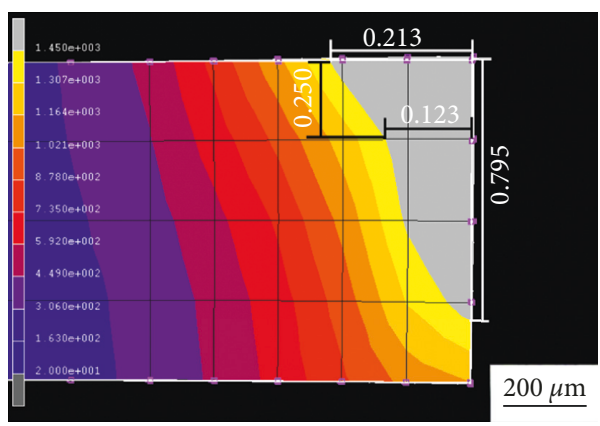

(b)

FigURE 9: Numerical simulation results of temperature distribution and weld profile: (a) $250 \mathrm{~W}, 2 \mathrm{~m} / \mathrm{min}$, and $0 \mathrm{~mm}$; (b) $250 \mathrm{~W}, 1.2 \mathrm{~m} / \mathrm{min}$, and $0 \mathrm{~mm}$.

a similar influence on the depth of penetration, weld width, waist width, and depth of the waist. This is because the welding speed determines residence time somewhere, when welding the material. The residence time is longer, and the bead width, waist width, and depth of the waist are larger. However, when the power increases, the area of keyhole increases and the keyhole deepens into the interior of the workpiece, which result in the increase of energy absorption and energy concentration in the lower part of the pool. The increase of laser power has no obvious effect on the shape of the upper part of the weld profile. So, the change of weld width, waist width, and depth of the waist is not obvious.

4.2. Simulation Results. Generally, A304 stainless steel melts at about $1400-1455^{\circ} \mathrm{C}[16]$. In this paper, the choice of the melt point is $1450^{\circ} \mathrm{C}$ [9]. For comparing the pool shape, the isotherm of the melting point is regarded as the fusion interface. Figure 9 shows the numerical simulation results of temperature distribution and weld profile at a point $42 \mathrm{~mm}$ along the welding direction using the combination heat source mode of cylindrical and cylindrical for two of the laser conditions: $250 \mathrm{~W}, 2 \mathrm{~m} / \mathrm{min}, 0 \mathrm{~mm}$ and $250 \mathrm{~W}$, $1.2 \mathrm{~m} / \mathrm{min}, 0 \mathrm{~mm}$. The depth of penetration of the weld is large, and the weld profile is nail shaped. The numerical simulation results of the depth of penetration, bead width, waist width, and depth of the waist are $0.770 \mathrm{~mm}$, $0.370 \mathrm{~mm}, 0.190 \mathrm{~mm}$, and $0.250 \mathrm{~mm}$, respectively, when the welding parameters are $250 \mathrm{~W}, 2 \mathrm{~m} / \mathrm{min}$, and $0 \mathrm{~mm}$. The numerical simulation results of the depth of penetration, bead width, waist width, and depth of the waist are $0.795 \mathrm{~mm}, 0.425 \mathrm{~mm}, 0.246 \mathrm{~mm}$, and $0.250 \mathrm{~mm}$, respectively, when the welding parameters are $250 \mathrm{~W}, 1.2 \mathrm{~m} / \mathrm{min}$, and $0 \mathrm{~mm}$.

\subsection{Comparison of Experimental and Simulation Results.} Figure 10 shows the comparison of experimental and simulation results for the depth of penetration, bead width, waist width, and depth of the waist for different powers. The error range of the depth of penetration, bead width, waist width, and depth of the waist between experimental and simulation results is about $4.8 \%, 3.6 \%, 15.6 \%$,

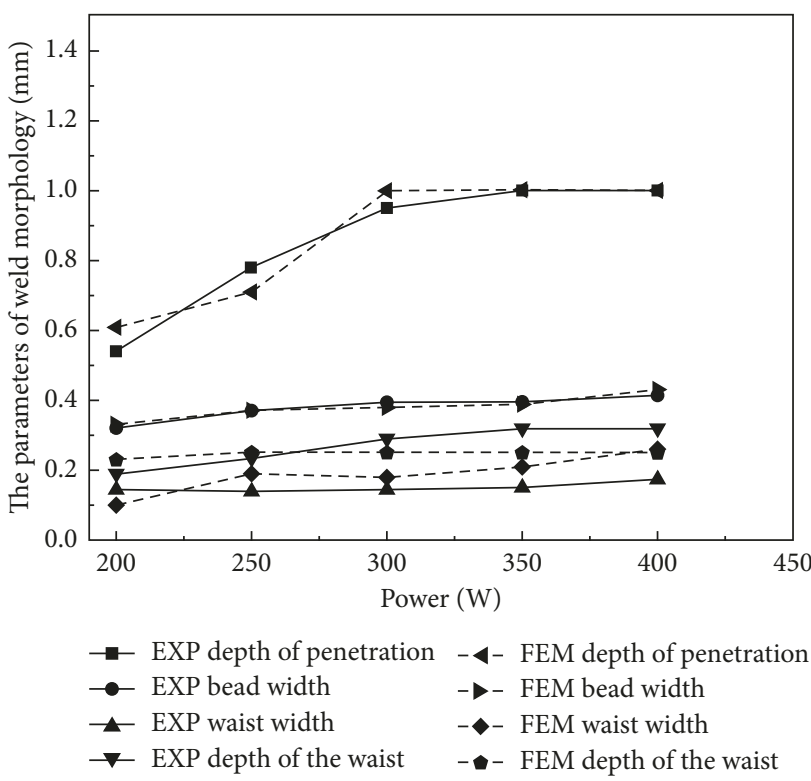

FIGURE 10: Comparison of experimental and simulation results for the depth of penetration, bead width, waist width, and depth of the waist for different powers.

and $18.9 \%$, respectively. Figure 11 shows the comparison of experimental and simulation results for the depth of penetration, bead width, waist width, and depth of the waist for different welding speeds. The error range of the depth of penetration, bead width, waist width, and depth of the waist between experimental and simulation results is about 3.6\%, $2.0 \%, 11.9 \%$, and $17.7 \%$, respectively. The error range of the depth of penetration and bead width is better than the error range of the waist width and depth of the waist. The possible reason may be that the flow of the fusion zone is not considered in simulation. The larger the fusion zone area of laser keyhole welding is, the higher the flow of the fusion zone is. The flow in the top of the fusion zone has obvious effect on the shape of the waist, while flow has no obvious influence on the heat transfer in the depth direction. This means that the flow of the weld pool is directional, and the material is isotropic in simulation. Combining with the literature [10-12], Table 5 shows the simulation error of six heat source modes about laser welding of the stainless steel 


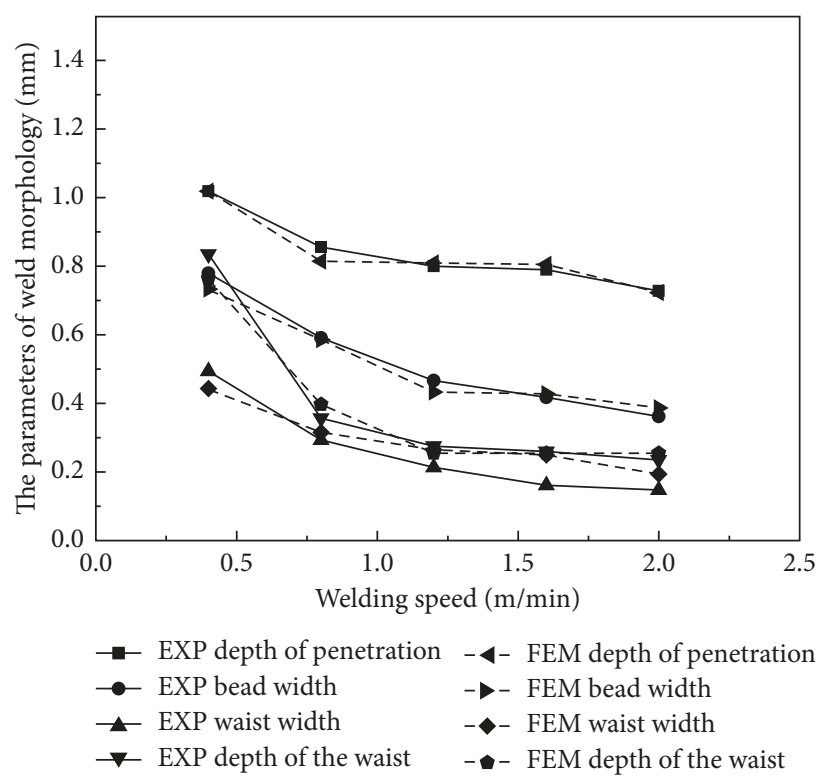

FIGURE 11: Comparison of experimental and simulation results for the depth of penetration, bead width, waist width, and depth of the waist for different welding speeds.

TABLE 5: Simulation error of six heat source modes about laser welding of the stainless steel sheet.

\begin{tabular}{|c|c|c|c|c|c|}
\hline \multirow[b]{2}{*}{ Heat source mode } & \multirow[b]{2}{*}{ Welding conditions } & \multicolumn{4}{|c|}{ Simulation error (\%) } \\
\hline & & $\begin{array}{l}\text { Weld } \\
\text { width }\end{array}$ & $\begin{array}{l}\text { Depth of } \\
\text { penetration }\end{array}$ & $\begin{array}{l}\text { Waist } \\
\text { width }\end{array}$ & $\begin{array}{l}\text { Depth of the } \\
\text { waist }\end{array}$ \\
\hline Conical and inverted conical [10] & $\begin{array}{l}\text { Pulsed laser butt welding of A304 } \\
\text { stainless steel with } 1 \mathrm{~mm} \text { thickness }\end{array}$ & 15.9 & 16.5 & - & - \\
\hline Conical [11] & $\begin{array}{l}\text { Continuous laser butt welding of } 316 \mathrm{~L} \\
\text { stainless steel with } 1.5 \mathrm{~mm} \text { thickness }\end{array}$ & - & 4.6 & - & - \\
\hline Double ellipsoid and conical [11] & $\begin{array}{l}\text { Continuous laser butt welding of } 316 \mathrm{~L} \\
\text { stainless steel with } 1.5 \mathrm{~mm} \text { thickness }\end{array}$ & - & 10.7 & - & - \\
\hline Conical and cylindrical [11] & $\begin{array}{l}\text { Continuous laser butt welding of } 316 \mathrm{~L} \\
\text { stainless steel with } 1.5 \mathrm{~mm} \text { thickness }\end{array}$ & - & 1.7 & - & - \\
\hline $\begin{array}{l}\text { Conical, inverted conical, and } \\
\text { ellipsoid [12] }\end{array}$ & $\begin{array}{c}\text { Continuous laser lap welding of } 301 \mathrm{~L} \\
\text { stainless steel with } 1 \mathrm{~mm} \text { and } 2 \mathrm{~mm} \\
\text { thicknesses }\end{array}$ & 4.0 & 8.0 & - & - \\
\hline Cylindrical and cylindrical & $\begin{array}{l}\text { Fiber laser butt welding of A304 stainless } \\
\text { steel with } 1 \mathrm{~mm} \text { thickness }\end{array}$ & $\begin{array}{c}4.1 \pm \\
1.6 / 1.2^{*}\end{array}$ & $2.9 \pm 2.0 / 0.9^{*}$ & $\begin{array}{c}13.6 \pm \\
7.4 / 3.8^{*}\end{array}$ & $18.3 \pm 8.0 / 3.3^{*}$ \\
\hline
\end{tabular}

* Minimum simulation error.

sheet. By comparing the simulation error of the combination heat source mode of cylindrical and cylindrical with the simulation error of other five heat source modes in Table 5, the results show that the simulation error of the heat source model of cylindrical and cylindrical is in the acceptable range. Figures 12 and 13 show the comparison of experimental and simulation results for the weld profile at a point $42 \mathrm{~mm}$ along the welding direction. The simulation results of the heat source model of cylindrical and cylindrical can match the actual shape of the weld well. So, it can be proved that a new combination heat source mode of cylindrical and cylindrical is established according to the results of error analysis and shape matching.

4.4. The Analysis and Results of the Temperature Field. Figures 14(a)-14(f) are the plots of the isothermal chart for one set of the parameter: laser power $450 \mathrm{~W}$, welding speed $1.4 \mathrm{~m} / \mathrm{min}$, focus position at $0 \mathrm{~mm}$, and six different time periods of $1.03 \mathrm{~s}, 2.06 \mathrm{~s}, 4.00 \mathrm{~s}, 14.29 \mathrm{~s}, 24.29 \mathrm{~s}$, and $144.30 \mathrm{~s}$, respectively. The figures clearly show the large temperature gradients at the area close to the laser source and the cooling of the workpiece away from the heat source. The total duration of the welding process is $4.29 \mathrm{~s}$. It is noted that there is a small preheated zone in front of the laser source. The maximum temperature of the melt pool is $2164^{\circ} \mathrm{C}$, which is far higher than the melting point of A304 stainless steel. In the middle of the workpiece, the heat source is in the form of ellipse on the surface of the workpiece. This elliptical shape of the molten pool varies depending on welding speed and beam power. In front of the melt pool, the isotherm is intensive and the temperature gradient is large. The isotherm behind the melt pool is more extensive. It seems from Figure $14(\mathrm{~d})$ that the maximal temperature of the melt pool is $164^{\circ} \mathrm{C}$ 

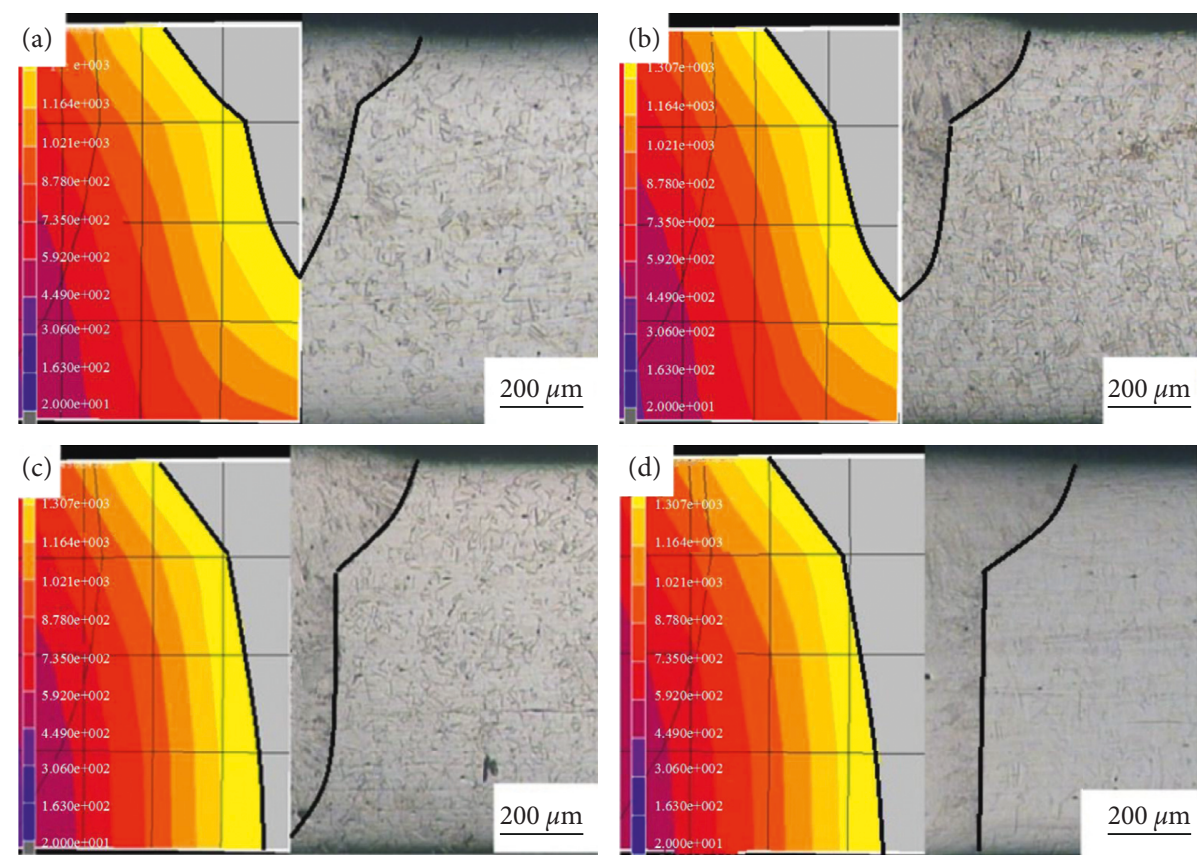

FIGURE 12: The comparison of experimental and simulation results of the weld profile for different laser powers in surfacing welding: (a) $200 \mathrm{~W}$, (b) $250 \mathrm{~W}$, (c) $300 \mathrm{~W}$, and (d) $350 \mathrm{~W}$.
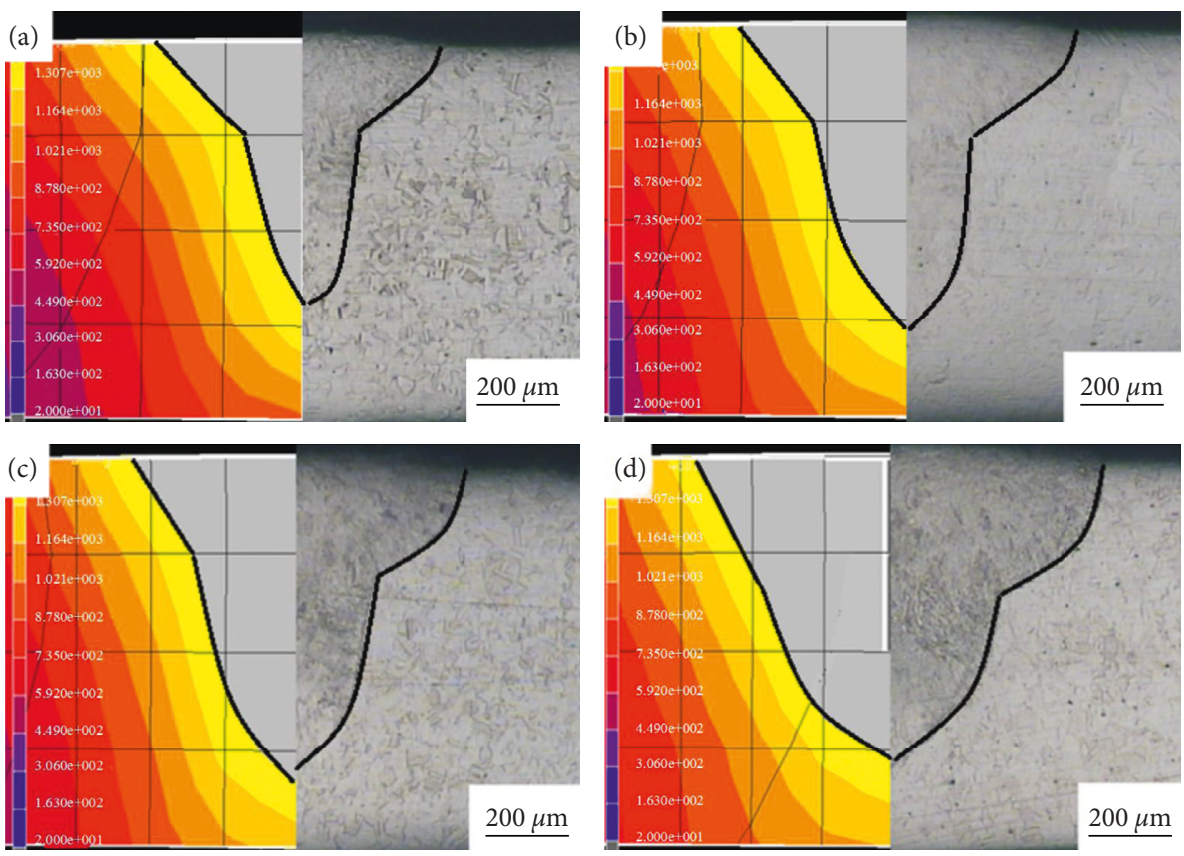

Figure 13: The comparison of experimental and simulation results of the weld profile for different welding speeds in surfacing welding: (a) $2 \mathrm{~m} / \mathrm{min}$, (b) $1.6 \mathrm{~m} / \mathrm{min}$, (c) $1.2 \mathrm{~m} / \mathrm{min}$, and (d) $0.8 \mathrm{~m} / \mathrm{min}$.

at $t=14.29 \mathrm{~s}$. After that, the cooling rate is getting lower and lower.

Schematic diagram of the point positions and thermal cycling curve of the laser welding are shown in Figure 15. When the heat source reaches the position of the point in the center line, the temperature reaches the maximum, and the heating rate is very high about $1.0 \times 104^{\circ} \mathrm{C} / \mathrm{s}$. After that, the heat source is far away, the temperature drops rapidly, and the cooling rate can be $1.4 \times 104^{\circ} \mathrm{C} / \mathrm{s}$. The tendency of the thermal cycling curve of each point is similar, which shows that the weld pool remains quasi-steady in the welding process, and the maximum temperature at each point is kept at about $2160^{\circ} \mathrm{C}$. The maximum temperature of each point vertical to the center line is different. Point $\mathrm{A}$ is in the center of the weld joint, so its maximum temperature is the highest. Points B, C, and D are in turn away from the center of the 

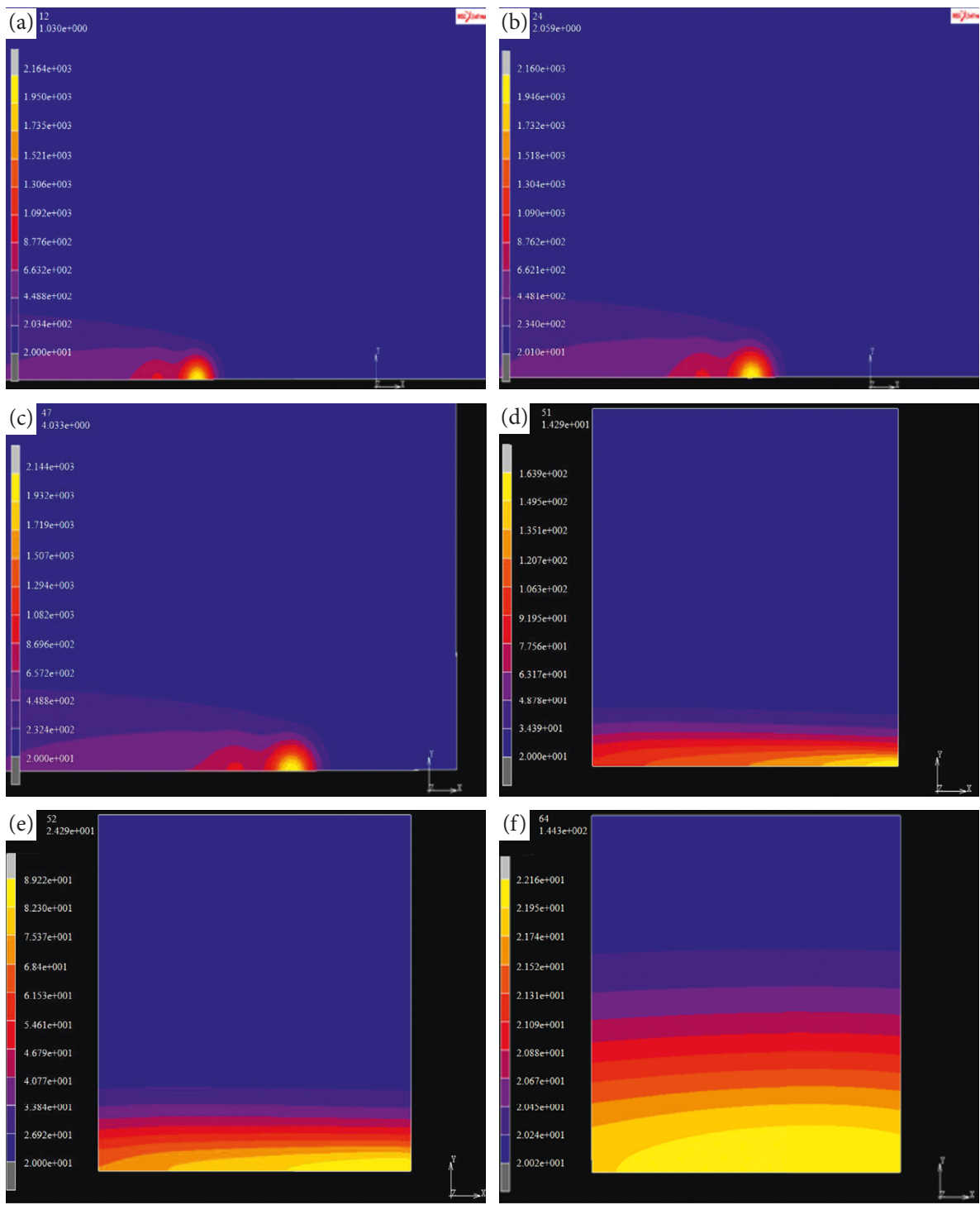

Figure 14: The temperature distribution in the laser welding process for different times: (a) $t=1.03 \mathrm{~s}$, (b) $t=2.06 \mathrm{~s}$, (c) $t=4.00 \mathrm{~s}$, (d) $t=14.29 \mathrm{~s}$, (e) $t=24.29 \mathrm{~s}$, and (f) $t=144.30 \mathrm{~s}$.

weld joint, and the maximum temperature is decreased. The closer to the center of the weld joint, the higher the rate of temperature increase and the cooling velocity. The maximum temperature of each point in direction of thickness varies little because the A304 stainless steel sheet is very thin.

\section{Conclusion}

This paper analyzes the change of the weld profile for laser butt welding of A304 stainless steel in different conditions. By a new heat source model and numerical simulation technology, the following conclusions are obtained:

(1) With the increase of laser power, the depth of penetration increases from 0.54 (at $200 \mathrm{~W}$ ) to $1.00 \mathrm{~mm}$ (at $400 \mathrm{~W}$ ), but the increase of weld width, waist width, and depth of the waist is not obvious. The increase of weld width, waist width, and depth of the waist is $0.322-0.415 \mathrm{~mm}, 0.145-0.175 \mathrm{~mm}$, and $0.190-0.320 \mathrm{~mm}$, respectively. The depth of keyhole increases as the laser power increases, so the depth of penetration is more sensitive to the welding power than bead width, waist width, and depth of the waist. The depth of penetration, bead width, waist width, and depth of the waist decrease with the increase of welding speed. The decrease of the depth of penetration, weld width, waist width, and depth of the waist is $1.00-0.715 \mathrm{~mm}$, $0.765-0.355 \mathrm{~mm}, 0.485-0.145 \mathrm{~mm}$, and $0.820-0.231 \mathrm{~mm}$, respectively. Welding speed has a similar influence on the depth of penetration, weld width, waist width, and depth of the waist.

(2) The simulation results of the heat source model of cylindrical and cylindrical can match the actual shape of the fiber laser welding feasibly. The error range of the depth of penetration, bead width, waist width, and depth of the waist between experimental and simulation results is about $4.1 \pm 1.6 \%, 2.9 \pm 2.0 \%, 13.6 \pm 7.4 / \%$, 

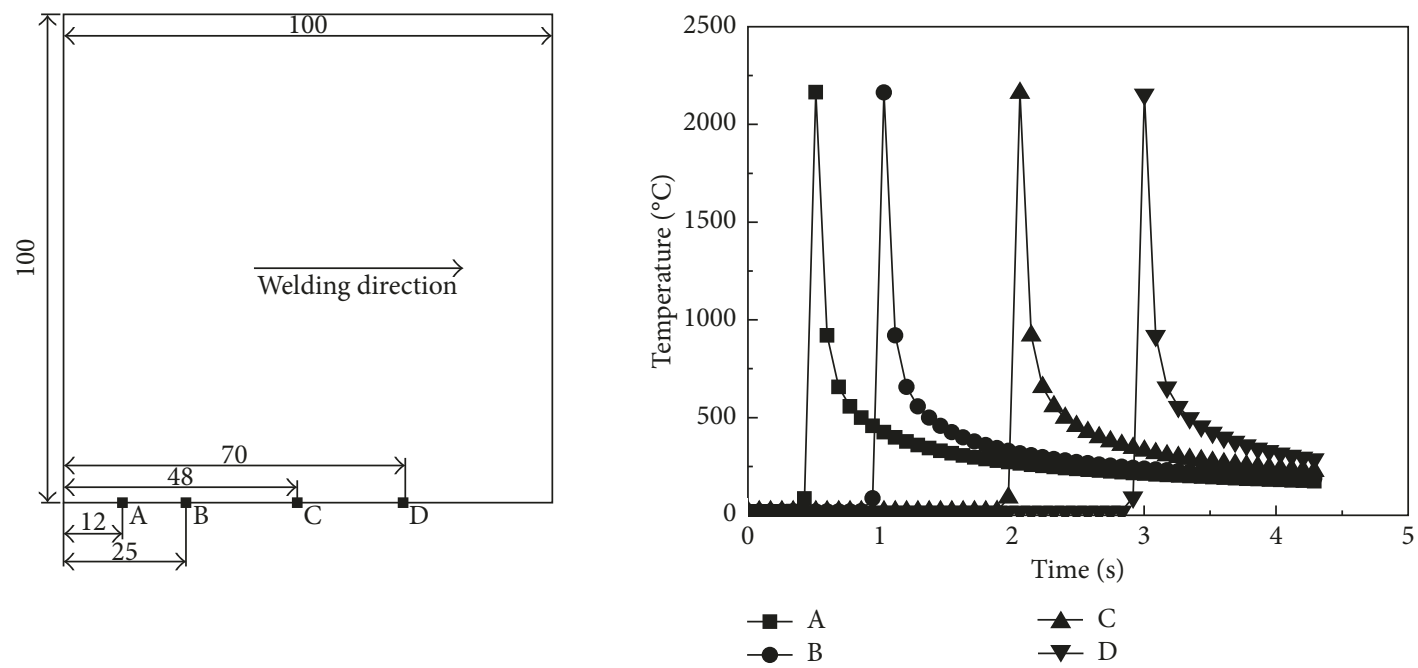

(a)

(b)
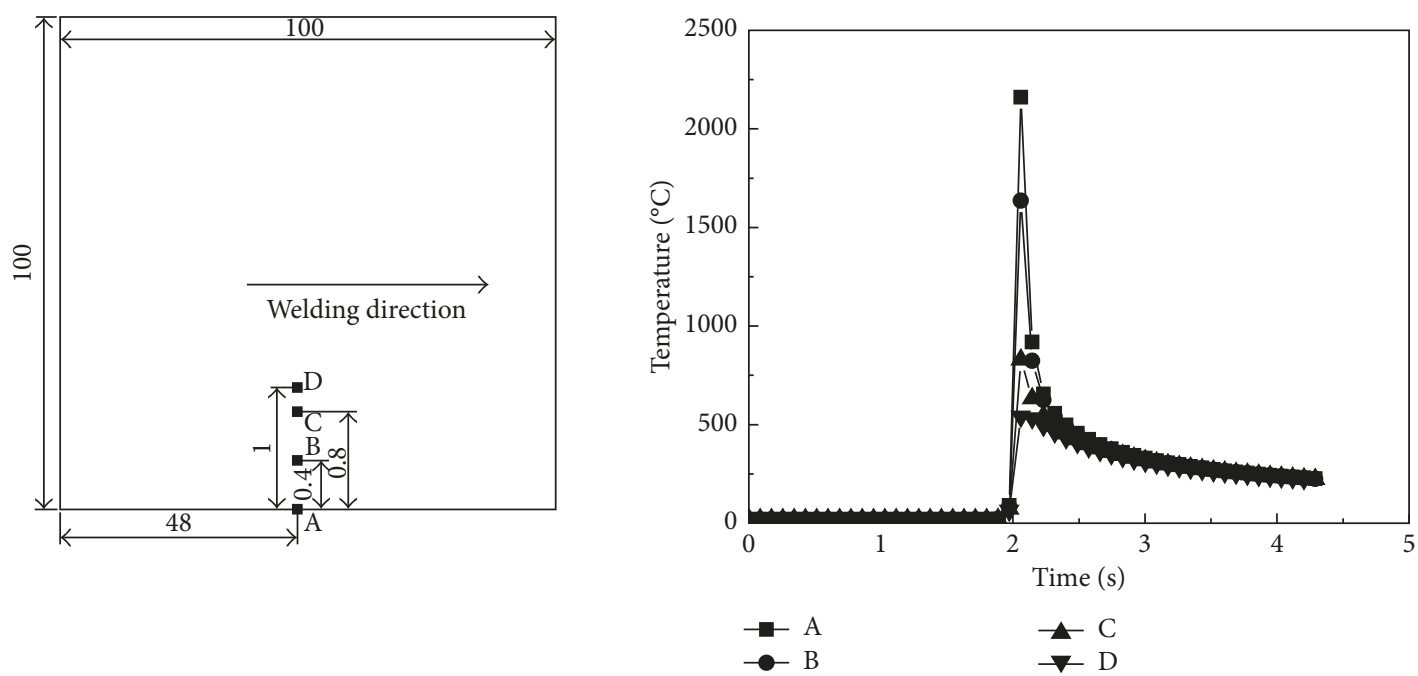

(c)

(d)
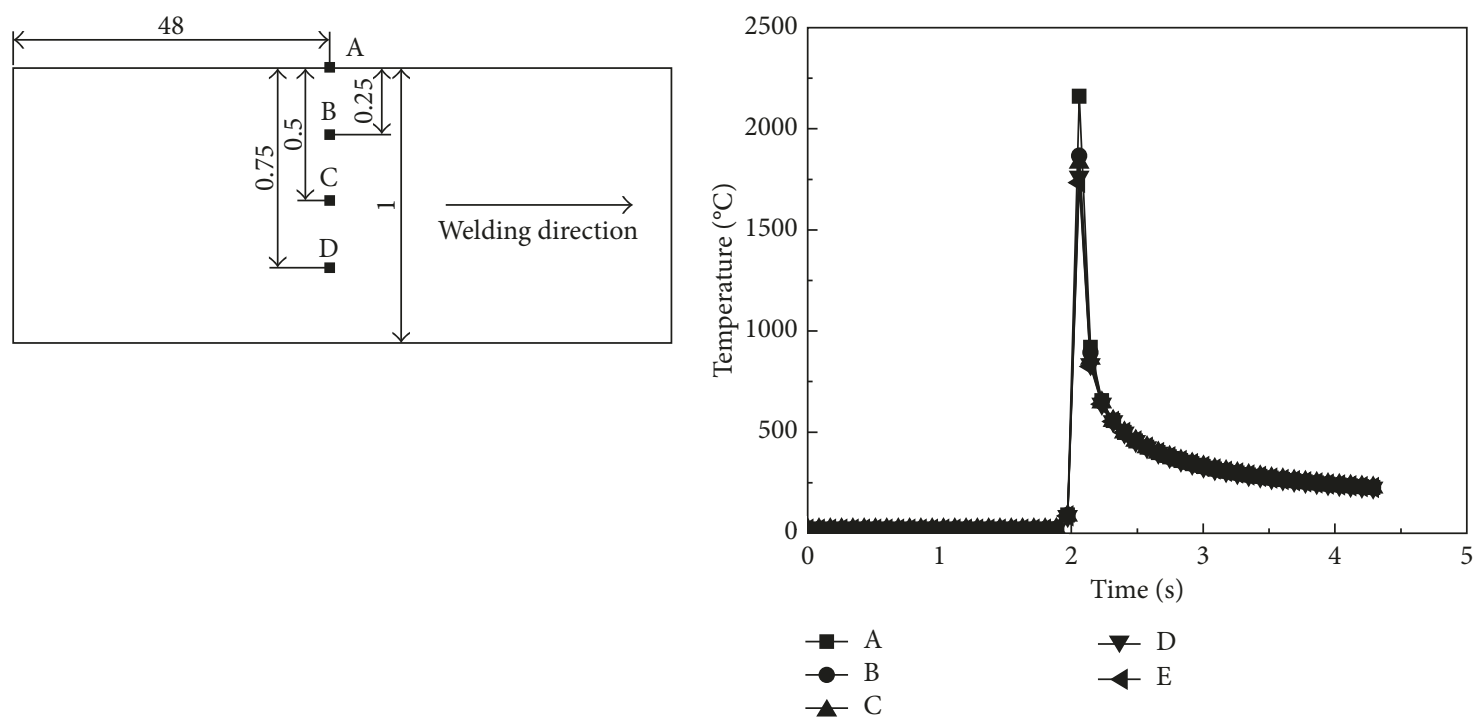

(e)

(f)

Figure 15: Schematic diagram of the point positions and thermal cycling curve of the laser welding: (a, b) center line, (c, d) vertical to the center line, and $(e, f)$ direction of thickness. 
and $18.3 \pm 8.0 \%$, respectively. The error range of the depth of penetration and bead width is better than the error range of the waist width and depth of the waist. The possible reason may be that the flow of the fusion zone is not considered in simulation.

(3) The heat source is in the form of ellipse on the surface of the workpiece. The maximum temperature of the melt pool is $2164^{\circ} \mathrm{C}$. The heating rate is about $1.0 \times 104^{\circ} \mathrm{C} / \mathrm{s}$, and the cooling rate can be $1.4 \times 104^{\circ} \mathrm{C} / \mathrm{s}$.

\section{Conflicts of Interest}

The authors declare that there are no conflicts of interest regarding the publication of this paper.

\section{Acknowledgments}

This work was supported by the Fundamental Research Funds for the Central Universities (2014QNA09), the Natural Science Foundation of Jiangsu (BK20150205), the Postdoctoral Science Foundation of Jiangsu (1501029A), and the China Postdoctoral Science Foundation (2016M591953).

\section{References}

[1] S. Daneshpour, S. Riekehr, M. Koçak, and C. H. J. Gerritsen, "Mechanical and fatigue behaviour of laser and resistance spot welds in advanced high strength steels," Science and Technology of Welding and Joining, vol. 14, no. 1, pp. 20-25, 2015.

[2] S. Lu, H. Fujii, and K. Nogi, "Marangoni convection and weld shape variations in $\mathrm{He}-\mathrm{CO}_{2}$, shielded gas tungsten arc welding on SUS304 stainless steel," Journal of Materials Science, vol. 43, no. 13 , pp. 4583-4591, 2008.

[3] A. Durgutlu, "Experimental investigation of the effect of hydrogen in argon as a shielding gas on TIG welding of austenitic stainless steel," Materials and Design, vol. 25, no. 1, pp. 19-23, 2004.

[4] M. Ma, Z. Wang, M. Gao, and X. Zeng, "Layer thickness dependence of performance in high-power selective laser melting of $1 \mathrm{Cr} 18 \mathrm{Ni}$ Ti stainless steel," Journal of Materials Processing Technology, vol. 215, no. 1, pp. 142-150, 2015.

[5] J. Yan, M. Gao, and X. Zeng, "Study on microstructure and mechanical properties of 304 stainless steel joints by TIG, laser and laser TIG hybrid welding," Optics and Lasers in Engineering, vol. 48, no. 4, pp. 512-517, 2010.

[6] X. Zhan, G. Mi, Q. Zhang, Y. Wei, and W. Ou, "The hourglasslike heat source model and its application for laser beam welding of $6 \mathrm{~mm}$ thickness 1060 steel," International Journal of Advanced Manufacturing Technology, vol. 88, no. 9-12, pp. 2537-2546, 2016.

[7] S. D'Ostuni, P. Leo, and G. Casalino, "FEM simulation of dissimilar aluminum titanium fiber laser welding using 2D and 3D Gaussian heat sources," Metals, vol. 7, no. 8, p. 307, 2017.

[8] A. Evdokimov, K. Springer, N. Doynov, R. Ossenbrink, and V. Michailov, "Heat source model for laser beam welding of steel-aluminum lap joints," International Journal of Advanced Manufacturing Technology, vol. 93, no. 1-4, pp. 709-716, 2017.

[9] A. P. Tadamalle, Y. P. Reddy, and E. Ramjee, "Influence of laser welding process parameters on weld pool geometry and duty cycle," Advances in Production Engineering and Management, vol. 8, no. 1, pp. 52-60, 2013.
[10] Y. C. Liao and M. H. Yu, "Effects of laser beam energy and incident angle on the pulse laser welding of stainless steel thin sheet," Journal of Materials Processing Technology, vol. 190, no. 1-3, pp. 102-108, 2007.

[11] K. R. Balasubramanian, N. Siva Shanmugam, G. Buvanashekaran, and K. Sankaranarayanasamy, "Numerical and experimental investigation of laser beam welding of AISI 304 stainless steel sheet," Advances in Production Engineering and Management, vol. 3, no. 2, pp. 93-105, 2008.

[12] N. S. Shanmugam, G. Buvanashekaran, and K. Sankaranarayanasamy, "Experimental investigation and finite element simulation of laser beam welding of AISI 304 stainless steel sheet," Experimental Techniques, vol. 34, no. 5, pp. 25-36, 2010.

[13] W. S. Chang and S.-J. Na, "A study on heat source equations for the prediction of weld shape and thermal deformation in laser microwelding," Metallurgical \& Materials Transactions B, vol. 33, no. 5, pp. 757-764, 2002.

[14] K. Kim, J. Lee, and H. Cho, "Analysis of pulsed Nd:YAG laser welding of AISI 304 steel," Journal of Mechanical Science \& Technology, vol. 24, no. 11, pp. 2253-2259, 2010.

[15] J. R. Chukkan, M. Vasudevan, S. Muthukumaran, R. Ravi Kumar, and N. Chandrasekhar, "Simulation of laser butt welding of AISI 316L stainless steel sheet using various heat sources and experimental validation," Journal of Materials Processing Technology, vol. 219, pp. 48-59, 2015.

[16] C. Shi, "Heat source model for partial penetration lap laser welding of stainless steel railway vehicles," Transactions of the China Welding Institution, vol. 32, no. 5, pp. 85-88, 2011.

[17] Y. Fan, Z. Chen, C. H. Zhang, and A. M. Liu, "A comparison of microstructure and mechanical properties of welded thin Ti6Al4V with three different types of laser," Material Research Innovations, vol. 19, no. S4, pp. S187-S192, 2015.

[18] Z. Xiong, "Numerical simulation of temperature field in deep penetration laser welding under hot and press condition," Transactions of the China Welding Institution, vol. 28, no. 8, pp. 41-44, 2007.

[19] D. F. Farson, J. F. Ready, and T. Feeley, LIA Handbook of Laser Materials Processing, Springer, Berlin, Germany, 2001.

[20] Y. Fan, W. Tian, Y. Guo, Z. Sun, and J. Xu, "Relationships among the microstructure, mechanical properties, and fatigue behavior in thin Ti6Al4V," Advances in Materials Science and Engineering, vol. 2016, Article ID 7278267, 9 pages, 2016.

[21] G. Tsoukantas and G. Chryssolouris, "Theoretical and experimental analysis of the remote welding process on thin, lap-joined AISI 304 sheets," International Journal of Advanced Manufacturing Technology, vol. 35, no. 9-10, pp. 880-894, 2008. 


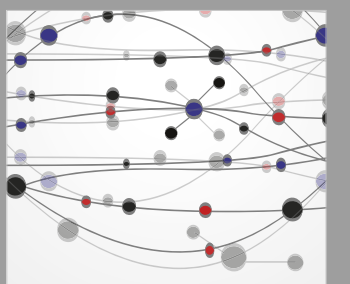

The Scientific World Journal
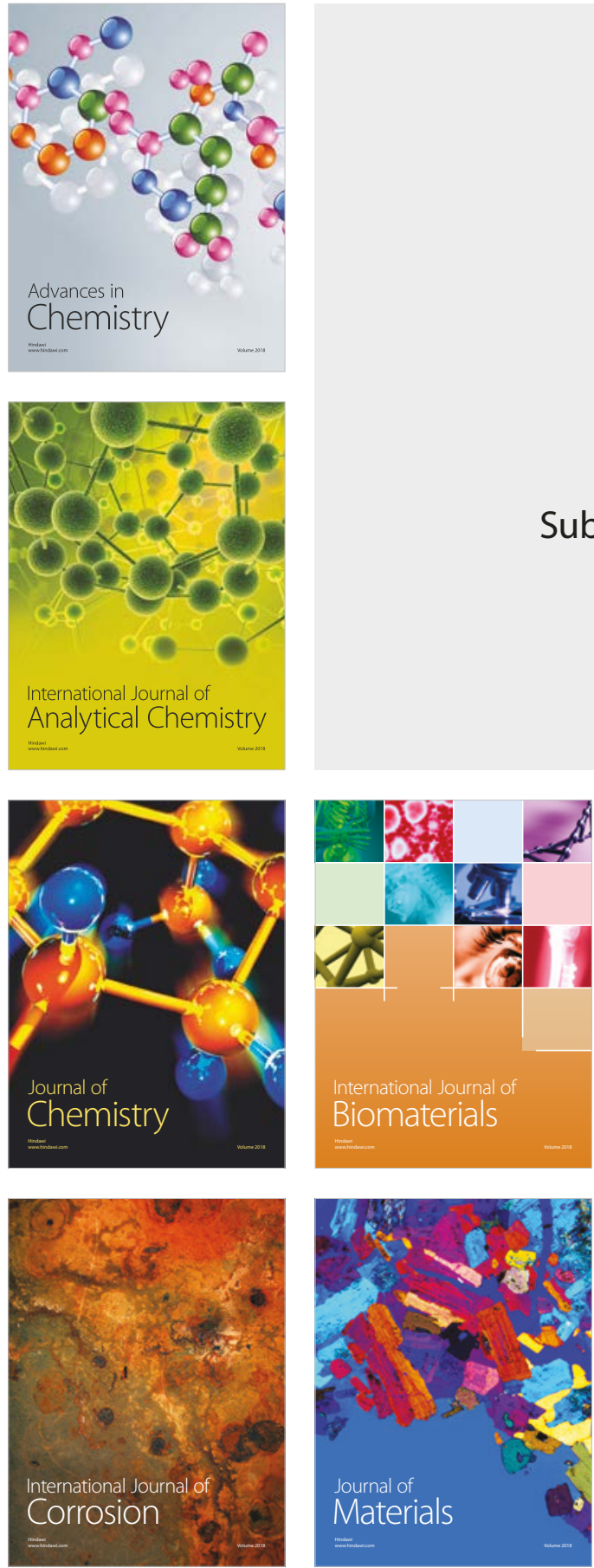

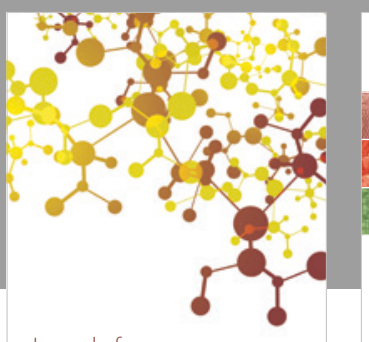

Journal of

Applied Chemistry
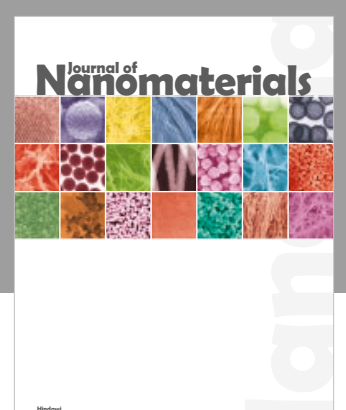

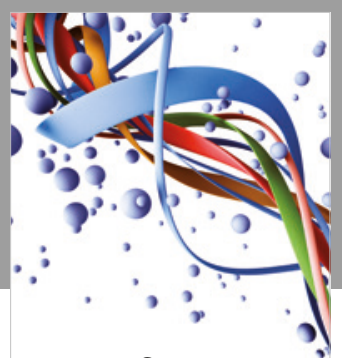

Scientifica

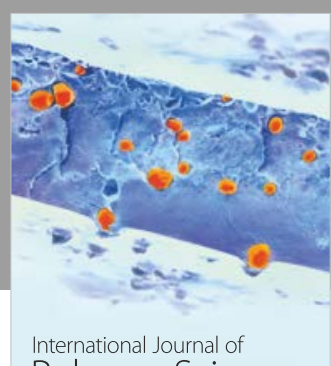

Polymer Science

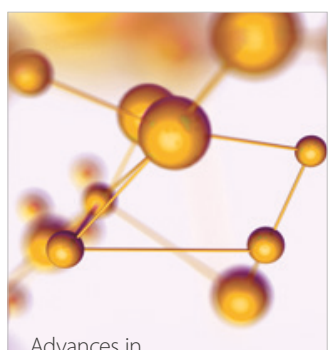

Physical Chemistry
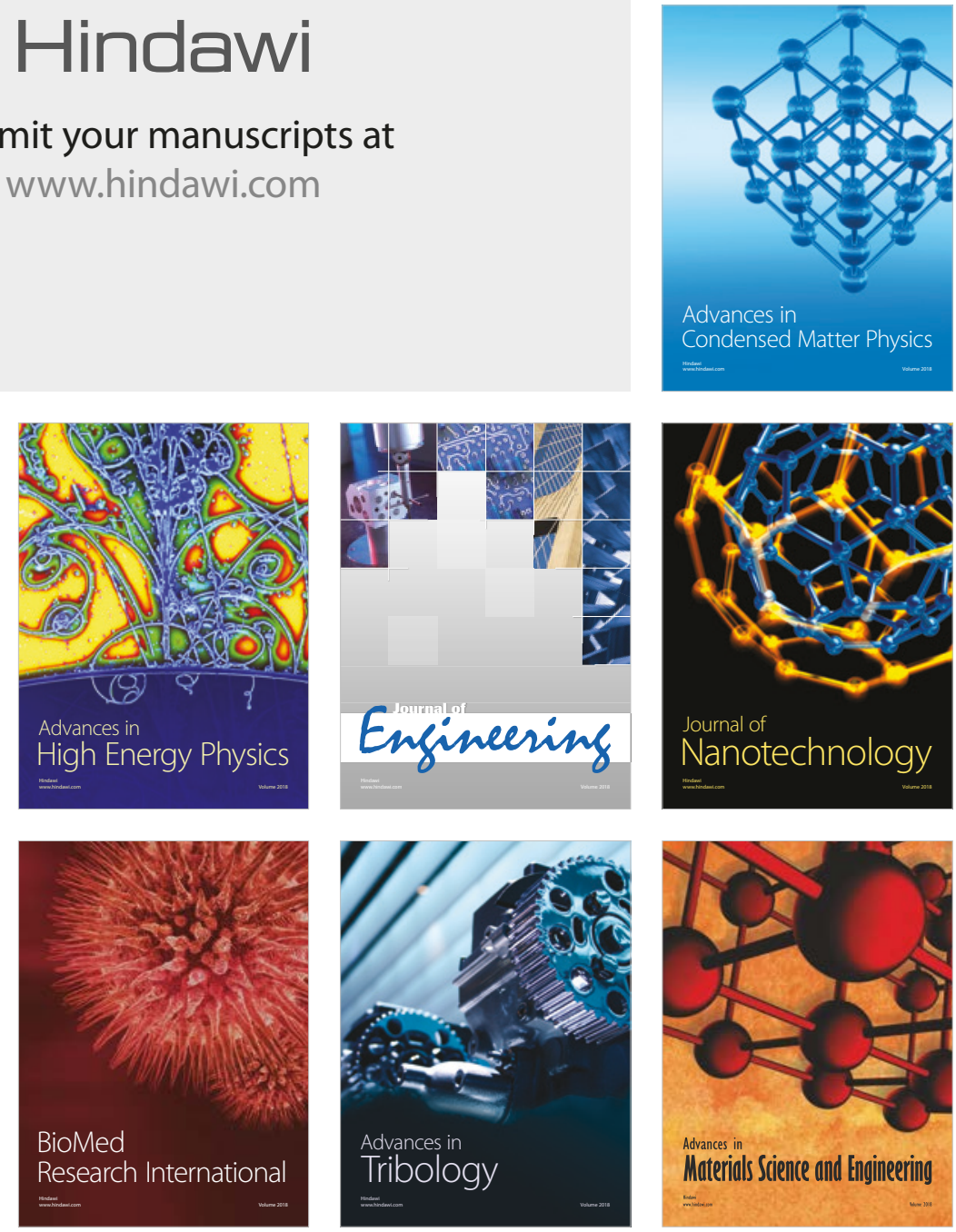